\title{
Impact Of Organizational Climate On Performance Of College Teachers In Punjab
}

\author{
Syed Ahmad Raza, Pir Mehr Ali Shah Arid Agriculture University, Pakistan
}

\begin{abstract}
The study aimed to determine the impact of organizational climate on performance of college teachers. The researcher selected the area of college education as the focus of the study. The study was delimited to all the public sector degree colleges of Punjab. Population of this study consisted of all the principals and teachers working in public sector degree colleges of Punjab and the simple random sampling technique sample was used. The sample consisted of 70 degree colleges, their heads, and five teachers from each sampled college. In order to measure the variables, the research instruments were the questionnaires for principals and teachers. Each questionnaire consisted of 30 items. The data collected from sampled colleges were tabulated, analyzed and interpreted in light of the objectives of the study by applying statistical tools of research, such as mean, standard deviation, standard error of means, and coefficient of correlation. On the basis of analysis, it was concluded that the majority of public college principals opined that open climate was very highly and positively correlated to teacher performance, but paternal and closed climates were negatively correlated to teacher performance. In light of the conclusions, it is recommended that teachers may be given chances to discuss their academic problems in groups, seminars, and conferences. Workshops may be arranged more for this purpose. The management style of principals may be improved through in-service training, seminars, workshops and departmental meetings and supervision. Performance of teachers can be increased by promoting open, as well as controlled, climates and avoiding closed climate. These climates may be ensured through administrative policy and measures.
\end{abstract}

Keywords: organizational climate, performance, principal, teacher, open climate, closed climate

\section{INTRODUCTION}

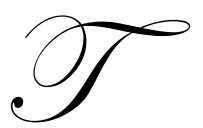

eachers play a basic and dynamic role in the educational system. It is said that good performance of students depends upon effective teaching of their teachers. One of the most difficult problems in educational research is that of recognizing the teacher effectiveness; i.e., discriminating between more effective and less effective teachers (Coleman, 1998). Teachers' performance is the way in which a teacher behaves in the process of teaching and it is known to be related to teachers' effectiveness. As professionals, college teachers need to be appropriate role models and exhibit to their students a commitment to scholarly values and to life-long learning (Medly and Shannon, 1994).

The concept of organizational climate of the organizations and other variables, including job satisfaction of the employees and their performance, began to emerge in the early 60's with the work of Halpin and Croft (1963) in this area. The exercise of refinement and modification of the instrument was carried on by his followers in the field and took into account the relationship of organizational climate and other variables, as organizational effectiveness, administrative styles, teachers' morale, leadership behavior, age, professional qualifications, job involvement, diffusion of innovations, quality of school life, social maturity of pupils and teacher effectiveness. Even though a handful of researches have been done with regard to organizational climate (Thompson, 2005; Allen, 2003; Volkwein and Zhou, 2003; and Johnsrud, Heck and Rosser, 2000), there is a lack of study carried out concerning organizational climate among higher education organizations' administrative staff, specifically in Pakistan. 
Aloofness refers to psychological and physical distance of a principal from the teachers. The degree of formality, holding of faculty meetings as business meetings and having tight meeting agendas, establishing firm rules for teachers and withholding results or classroom visits are indicative of principals' aloofness.

Production emphasis is the leadership behaviour of the principal that is characterized by degree of active supervision, degree of assertiveness in the supervisory role, scheduling teachers' work, correcting teachers' mistakes, doing most of the talking, and seeing to it that teachers work hard.

Thrust involves the active, energetic, role-modeling aspect of the principal's behavior. Personal drive and vigor, arriving early and staying late, setting a good example by working hard and being active and interested in new educational developments are other features of this sort of behavior.

Consideration is treating staff members as human beings. Kindness, humanitarianism, doing personal favour for teachers, helping them both in their work and in their personal lives, and standing up for the teachers' best interests are characteristic features of this aspect of leadership behaviour of the principal (Halpin, 1966).

Disengagement behaviour is characterized by the teachers' psychological and physical distance from each other and from the college as a whole. Teachers with high disengagement bicker and criticize each other, form cliques, annoy each other and contemplate leaving.

Abundance of clerical tasks and responsibilities unrelated to teaching are salient features of hindrance. Teachers are overloaded with busy work, paper work, committees, reports and routine duties.

Morale, spirit and liveliness of the group of teachers are characteristic features of esprit. Other features have being cheerfulness and commitment of teachers to education, enjoying each other and being mutually respectful and helpful, working energetically and showing loyalty to the college.

Intimacy refers to the degree to which teachers share their private lives with each other and exchange confidences. Teachers with intimacy socialize together outside college, visit each other's homes, discuss private matters deeply and establish close friendships (Halpin, 1966).

The study of four aspects of principals' leadership behaviour and four aspects of teachers' behaviour help us categorize organizations into six distinct profiles of configurations in line with Halpin and Croft (1966). The six profiles found in the organizations can be regarded as six distinct organizational climates; namely, Open, Autonomous, Controlled, Familiar, Paternal and Closed.

An open climate describes the openness and authenticity of interaction that exists among the principal, teachers, students and parents. Hoy and Sabo (1998) state that an open climate reflects the principal's and teachers' cooperatives, supportive and receptive attitudes to each other's ideas and their commitment to work. The principal shows genuine concern for teachers, motivates and encourages staff members, gives the staff freedom to carry out their duties in the best way they know, and does not allow routine duties to disrupt teachers' instructional responsibilities. They care, respect and help one another as colleagues and even at a personal level (Halpin 1966).

Autonomous climate portrays an atmosphere where teachers are given a good measure of freedom to operate in the institution. The principal models enthusiasm and diligence. Both teachers and students are happy. There is no external threat or influence. Teachers have great desire to work and students are highly motivated to learn.

Hard work is the major characteristic of the controlled climate. The principal often employs a direct approach, keeps his/her distance from teachers, students and parents in order to avoid familiarity.

Familiar climate depicts a laissez-faire atmosphere. The principal is concerned about maintaining a friendly atmosphere at the expense of task accomplishment. Thus, a considerable percentage of teachers are not committed to their primary assignment. Some who are committed resent the way the principal runs the college; they 
do not share the same views with the principal and their colleagues. As a result, those who are not committed form a clique because they share the same attitude and they become friends. Familiarity between the principal and teachers is so much that the college work suffers.

Paternal climate depicts an atmosphere where the principal is very hardworking, but has no effect on the staff; to them, hard work is not a popular term. There is a degree of closeness between the principal and teachers, but the principal's expectation from teachers is rather impractical. All the same, he/she is considerate and energetic, but his/her leadership approach is benevolently autocratic. As a result, most teachers, students and parents prefer to maintain distance from the principal. Often students cannot express their difficulties or problems with boldness and parents visit the college only when it is absolutely necessary.

Closed climate represents the 'antithesis of the open climate'. The main characteristic of this type of climate identified by Halpin (1966) is lack of commitment and/or non-productivity. There is no commitment, especially on the part of the principal and teachers. The principal is rigid and controlling, inconsiderate, unsupportive and unresponsive. Consequently, most teachers are frustrated, ineffective, and lack of respect for the principal (Silver 1983; Halpin 1966), (Costley and Todd, 1987), and (Hoy and Sabo (1998).

\section{STATEMENT OF THE PROBLEM}

The major objective of the study was to find the impact of organizational climate on performance of teachers in public sector degree colleges of Punjab.

\section{OBJECTIVES}

The objectives of the study were: 1) to identify the strengths of the organizational climates of public degree colleges, as perceived by the principals and teachers; 2) to identify the weaknesses of the organizational climates of public degree colleges, as perceived by the principals and teachers; and 3) to measure the performance of the teachers, as perceived by the principals of the colleges.

\section{METHOD}

\section{Population}

The population of the study consisted of the following categories of respondents:

1. Principals of all 311 public degree colleges in Punjab.

2. All the teachers working in these colleges.

\section{Sample}

For choosing the sample from the population the simple random sampling technique was used. The sample of this study is shown in Table 1.

Table 1: Distribution of Sample Colleges

\begin{tabular}{|l|c|c|c|c|}
\hline \multirow{2}{*}{ Category } & \multicolumn{2}{|c|}{ Principals } & \multicolumn{2}{c|}{ Teachers } \\
\cline { 2 - 5 } & Male & Female & Male & Female \\
\hline Public & 35 & 35 & 175 & 175 \\
\hline
\end{tabular}

\section{Research Instrument}

After going through the related literature, the researcher prepared two questionnaires for principals and teachers using a five-point Likert scale. The questionnaires comprised of items mainly about the organizational 
climate (aspects of principal and teacher behaviours) and teacher performance. These behaviour aspects are described by Halpin and Croft (1966). The first questionnaire consisted of a total of 30 items regarding organizational climate. The first 16 items were regarding the principal behaviour aspects (aloofness, production emphasis, thrust and consideration) and the remaining 14 items were regarding the teachers' behaviour aspects (disengagement, hindrance, esprit and intimacy). This questionnaire, developed for teachers and principals, asked for the information regarding their gender and experience (teaching, administration). The second questionnaire consisting of a total of 30 items, developed for teachers and principals, asked for the information regarding teacher performance.

\section{Pilot Testing of Questionnaires}

The pilot-testing of questionnaires was conducted in March, 2006. The researcher personally visited five public degree colleges and administrated the questionnaires among their principals and 25 members of the teaching faculty (five from each college).

\section{DATA COLLECTION}

The researcher visited most of the colleges and administered the questionnaires in person. The data from the remaining sample colleges were collected through his friends, ex-colleagues and research fellows. The response rate was 100 percent from the respondents. The whole process of data collection was completed in three months.

\section{DATA ANALYSIS}

The responses obtained through the above-mentioned research instruments were scored before statistical analysis and interpretation. After scoring of the organizational climate descriptive questionnaire, data were collected from sampled colleges. Scores of all the items measuring each of the four aspects of principals' behaviour and four aspects of teachers' behaviour were calculated separately for each of the respondents of a college and added up. On the basis of these calculations, the sampled colleges were further divided into six types of organizational climates; namely, Open, Autonomous, Controlled, Familiar, Paternal and Closed. The most suitable statistical tools like mean, standard deviation, standard error of means and coefficient of correlation (r) were used to obtain the results.

\section{RESULTS AND DISCUSSION}

Tables available from author at drahmadrazashah@yahoo.com.

\section{DISCUSSION}

The basic objective of the study was to determine the impact of organizational climate on performance of teachers in public degree colleges. The results of the study support that organizational climate and performance of the teachers are correlated. Coefficient of correlation showed organizational climate to be significantly correlated to teachers' performance with different aspects of principals' and teachers' behaviours. The study established a significant correlation between organizational climate and performance of college teachers teaching in degree colleges.

The study results revealed that a vast majority of public degree colleges had open and autonomous climates. Teachers in open and autonomous climates showed much better performance than the teachers in paternal or closed climates. This strengthens the notion of Halpin and Croft (1966) that most of the features of behaviours and reactions of principals and teachers in paternal and closed climates are disliked by the teachers and they feel uneasy, which negatively impacts on their performance.

The study results revealed that the opinions of principals, regarding esprit behaviour of teachers and production emphasis behaviour of principals, substantially correlated to teachers' performance. The majority of the principals opined that consideration and aloofness behaviours of principals are negatively correlated to teachers' performance. Intimacy behaviour of teachers is slightly correlated to teachers' performance and disengagement 
behaviour negatively correlated to teachers' performance. Kimberly (2007) supports findings on disengagement behaviour of teachers as he focuses on teachers' burnout prevention models.

The study results revealed that the majority of the college teachers viewed 'consideration' behaviour of principals and 'intimacy' behaviour of teachers fairly correlate to teachers' performance. The majority of the teachers viewed that 'thrust' behaviour of principals and esprit behaviour of teachers is highly correlated to teachers' performance. The majority of the teachers expressed that 'production emphasis' behaviour of principals and 'hindrance' behaviour of teachers moderately correlated with teachers' performance. The majority of the teachers opined that 'disengagement' behaviour of teachers slightly correlated with teachers' performance while 'aloofness' behaviour principals negatively correlated with teachers' performance. The findings of the studies of Friesen (1972) and Singh (1985) were the same.

In this study, college teachers opined that open climate was very highly autonomous and controlled climates were substantially positively correlated with teacher performance, while paternal and closed climates were negatively correlated with teacher performance. These findings had the support of a previous study by Singh (1985) who found that teachers in a more open climate performed much better than teachers in a less open climate. Their findings revealed that most of the schools run an open climate type of organization.

\section{AUTHOR INFORMATION}

Syed Ahmad Raza Shah is presently Ph.D. scholar in the University Institute of Education and Research, Pir Mehr Ali Shah Arid Agriculture University, Rawalpindi, Pakistan.

\section{REFERENCES}

1. Allen, D. K. (2003). Organizational Climate and Strategic Change in Higher Education: Organizational Insecurity. Journal of Higher Education, 46(1): 61-92.

2. Coleman, B. 1998. Perspectives on Classrooms and Schools. The Open University Press, London, UK. p. 100-101.

3. Costley, D. L. and R. Todd. 1987. Human Relations in Organizations. 3rd edition. West Publishing, St. Paul. P. 562

4. Friesen, D. 1972. Variations in perceptions of organizational climate. Alberta Journal of Educational Research, 18(2):23-31.

5. Halpin, A.W. 1966. Change and organizational climate. Journal of Educational Administration, 10(1): 3881.

6. Halpin, A. W. and D. B. Croft. 1963. The Organizational Climate of Schools: Midwest Administration Center. University of Chicago, Chicago, USA. p. 89-110.

7. Hoy, W. K. and Sabo, D. J. 1998. Quality Middle School: Open and Healthy. Corwin Press Inc, California. P.11-14, 125-129.

8. Johnsrud, L. K., Heck, R. H., and Rosser, V. J. (2000). Morale matters: Midlevel Administrators and their intent to leave. Journal of Higher Education, 71: 34-59.

9. Kimberly, E. M. 2007. A System Thinking Approach to Educational Reform: Addressing Issues Surrounding Teacher Burnout Through Comprehensive School Change. (Unpublished) Doctoral dissertation, Oregon State University, USA.

10. Medly, D. M. and D. N. Shannon. 1994. Teacher Education. The International Encyclopedia of Education System, Oxford. 10(2): 6015-6020.

11. Silver, P. F. 1983. Educational Administration: Theoretical Perspectives on Practice and Research, Harper and Row Publishers, New York. pp. 45-66, 180-184.

12. Singh, S. 1985. A study of school climate, leadership behavior and moral development of the heads of elementary and secondary schools. (Unpublished) Doctoral dissertation, Punjab University, India. 162 pp.

13. Volkwein, J. F. and Y. Zhou. 2003. Testing a model of administrative job satisfaction. Research in Higher Education, 44(2): 149-171. 
NOTES 